\title{
Effect of Interface Structure on Microstructural Evolution in Polycrystals
}

\author{
John G. Fisher and Suk-Joong L. Kang* \\ Department of Materials Science and Engineering, Korea Advanced Institute of Science and Technology, \\ 335 Gwahangno, Yusong-gu, Daejon 305-701, Republic of Korea. \\ *corresponding author. Tel: +82-42-350-4113, 8919; Fax: +82-42-350-3310,8920; email: \\ sjkang@kaist.ac.kr
}

\begin{abstract}
.
Control of microstructure during processing is necessary to produce materials with optimum properties. Grain growth behaviour in both two-phase (solid/liquid) and single phase materials is strongly dependant on interface structure, either rough (atomically disordered) or faceted (atomically ordered). Materials with disordered interfaces show normal grain growth behaviour, whereas materials with ordered interfaces can show different types of non-normal grain growth, which are system and timedependant: pseudo-normal, abnormal, stagnant and delayed abnormal. Examples of the different types of grain growth are given from ceramic and metallic systems, and general principles of microstructure evolution with respect to interface structure are presented.
\end{abstract}

Keywords: microstructural evolution, grain growth, abnormal grain growth, interface structure, 2D-nucleation

\section{INTRODUCTION}

During thermal processing of materials, grain growth often takes place. Small grains are consumed by larger grains and the average grain size increases with processing time. The driving force for grain growth is the reduction of the total interfacial (grain boundary or solid/liquid) energy. Grain growth necessitates diffusion of mass from one grain to another and movement of interfaces. Examples of processes where grain growth takes place include sintering of ceramic and powder metallurgical parts, growth of thin/thick films and annealing of cold-worked metals.

Control of grain growth behaviour during processing is important because the grain size has important effects on the mechanical and electrical properties of materials. In this paper, an overview will be given of our work carried out on grain growth and microstructure evolution, with an emphasis on the effect of interface structure. First, theories of grain growth in two-phase polycrystalline materials with different types of solid/liquid interface will be described, followed by examples of behaviour in real systems. Examples from single phase materials will also be given. Although most of the work has been carried out on ceramics, the theories presented are also applicable to grain growth in metals.

\section{Grain Growth in Two-Phase Systems}

Ceramics are often sintered in the presence of a small amount of a liquid phase, either formed by a deliberately added sintering aid or by impurities in the powder. The driving force for sintering is the difference in solubility between large and small grains caused by differences in curvature. If the solid phase is soluble and dispersed in the liquid phase, then small grains have a higher solubility in the liquid phase than large grains and grain growth takes place by Ostwald ripening. This grain growth behaviour was first analysed rigorously by Lifshitz and Slyozov ${ }^{1}$ and Wagner $^{2}$ to give the classic LSW theory. Using the derivation of Greenwood, the growth rate of a grain of radius $r$ is given by: ${ }^{3,4}$

$$
\frac{d r}{d t}=\frac{2 D C_{\infty} \gamma \Omega}{k T r}\left(\frac{1}{-}-\frac{1}{r}\right)=\frac{D C_{\infty}}{k T} \times \frac{\Delta \mathrm{g}}{r}
$$

where $C_{\infty}$ is the equilibrium solubility, $D$ the diffusion coefficient of the solute in the liquid, $k$ the Boltzmann constant, $T$ the absolute temperature, $\gamma$ the solid/liquid interfacial energy, $\Omega$ the atomic volume of the solid phase, $\bar{r}$ the mean grain radius and $\Delta g=2 \gamma \Omega\left(\frac{1}{\bar{r}}-\frac{1}{r}\right)$ the driving force for grain growth.

If the curve of growth rate versus grain radius is plotted, it is seen that grains with $r<\bar{r}$ are shrinking and grains with $r>\bar{r}$ are growing, with a maximum in growth rate at $r=2 \bar{r}$. Upon extended sintering, the relative grain size distribution (i.e. the distribution of values of $r / \bar{r}$ ) becomes stationary, with a maximum grain size of $1.5 \bar{r} .^{3}$ In particular, abnormal grain growth will not take place.

LSW theory makes several assumptions, the most important of which is that the interface mobility is constant i.e. it does not change with changes in the driving force or the crystallographic orientation of the grain surface. ${ }^{3}$ This assumption of constant mobility is only true for grains with an isotropic solid/liquid interfacial energy i.e. the interfacial energy is the same regardless of crystallographic orientation of the grain surface. Such grains appear macroscopically spherical and have interfaces that are disordered (rough) on an 
atomic scale. Due to the disordered interface, there are an unlimited number of sites at which atoms can attach to or detach from the grain surface. In this case, grain growth is limited by the rate at which atoms diffuse through the liquid phase to the growing grain. A schematic plot of grain growth rate vs. driving force $\Delta \mathrm{g}$ for a disordered interface is shown in Fig. 1 (the dashed line). For a disordered interface, the growth rate increases almost linearly with driving force as shown (To obtain a truly linear graph, growth rate should be plotted vs. $\Delta \mathrm{g} / r$; but the non-linearity caused by neglecting $r$ is not significant.). All grains with a positive driving force can grow and abnormal grain growth will not occur. Examples of such systems include $\mathrm{Pb}\left(\mathrm{Mg}_{1 / 3} \mathrm{Nb}_{2 / 3}\right) \mathrm{O}_{3}-35 \mathrm{~mol} \% \mathrm{PbTiO}_{3},{ }^{5} \mathrm{NbC}-\mathrm{Co}-$ $\mathrm{B}^{6}$ and $2 \mathrm{CaO} . \mathrm{SiO}_{2}$ in a silicate melt. ${ }^{7}$

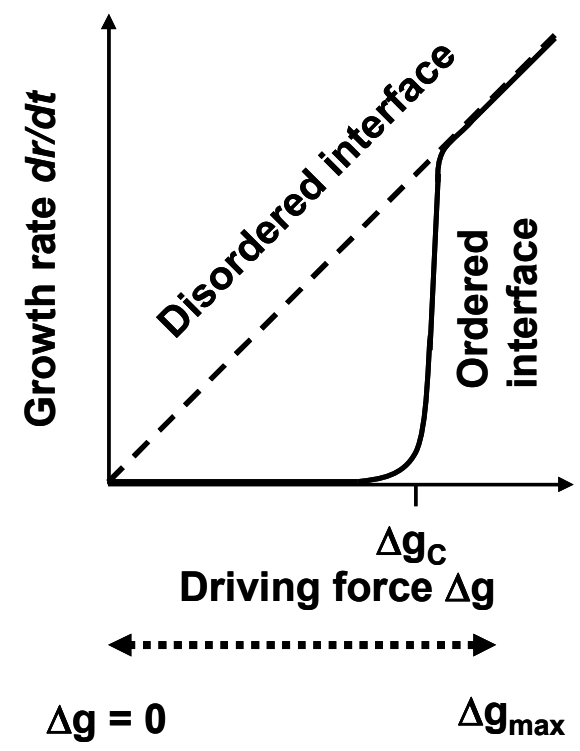

Figure 1 Variation of grain growth rate with driving force for disordered and ordered interfaces.

However, if the solid/liquid interfacial energy is anisotropic with the crystallographic orientation of the grain surface, then the grain growth behaviour can be very different. In this case, the grains will appear microscopically faceted and will be bounded by surfaces which have low solid / liquid interfacial energies. On an atomic scale, the interfaces will appear ordered, with flat or stepped surfaces. Atoms attaching to the grain surface will have a high number of broken bonds and will be unstable. The atoms will eventually desorb from the surface unless they can move to a more favourable site. Such sites include 2D nuclei, ${ }^{8}$ screw dislocations, ${ }^{9,10}$ polytypic phases ${ }^{11,12}$ and re-entrant edges such as twins. ${ }^{13,14}$ For grains with ordered boundaries, the interface mobility is no longer constant i.e. it can vary with driving force. For a grain with ordered interfaces growing by $2 \mathrm{D}$ nucleation and growth, the growth rate can be given by the equation: ${ }^{15}$

$$
\frac{d r}{d t}=v_{s t} \exp \left(\frac{-\pi \Omega \varepsilon^{2}}{6 h \Delta \mathrm{g} k T}\right)
$$

where $v_{s t}$ is the step velocity of the growing nucleus, $\varepsilon$ the step free energy of the nucleus, $h$ the step height of the nucleus, and $k, T$ and $\Delta \mathrm{g}$ have the same meanings as in equation [1]. A schematic plot of grain growth rate vs. driving force $\Delta \mathrm{g}$ for an ordered interface growing by $2 \mathrm{D}$ nucleation and growth at $\Delta \mathrm{g} \leq \Delta \mathrm{g}_{\mathrm{C}}$ is shown in Fig. 1 (the solid line). The variation of growth rate with driving force is no longer linear, but exponential. Below a critical driving force $\Delta \mathrm{g}_{\mathrm{C}}$, the rate at which stable 2D nuclei form on the grain surface is very low: therefore the majority of atoms which attach to the grain will desorb again and the grain growth rate is very low. At the critical driving force, the rate at which stable 2D nuclei form increases rapidly. The majority of atoms which attach to the grain can now find a 2D nucleus to attach to and the grain growth rate increases rapidly. For values of $\Delta \mathrm{g}>\Delta \mathrm{g}_{\mathrm{C}}$, grain growth is now controlled by the rate of diffusion of atoms though the liquid phase, as in the case of a disordered interface, because the rate of diffusion of atoms is slower than the rate of interface reaction. The grain growth rate now increases linearly with driving force, as shown in Fig. 1. The value of the critical driving force is given by: ${ }^{15}$

$$
\Delta \mathrm{g}_{\mathrm{C}}=\frac{\Omega \varepsilon^{2}}{3 h k T}
$$

For a system with ordered interfaces, grain growth behaviour is non-normal (i.e. the relative grain size distribution with annealing time is non-stationary) and can vary depending on the relative values of $\Delta \mathrm{g}_{\mathrm{C}}$ and the driving force for growth of the largest grain, $\Delta \mathrm{g}_{\max } \cdot{ }^{16,17}$ If $\Delta \mathrm{g}_{\mathrm{C}}<\Delta \mathrm{g}_{\max }$, then a large number of grains will have $\Delta \mathrm{g}>\Delta \mathrm{g}_{\mathrm{C}}$. Many grains will grow and pseudo-normal grain growth will result. If $\Delta \mathrm{g}_{\mathrm{C}} \approx \Delta \mathrm{g}_{\max }$, then most of the grains will have $\Delta \mathrm{g}<\Delta \mathrm{g}_{\mathrm{C}}$ and will grow very slowly. A small number of grains will have $\Delta \mathrm{g} \geq \Delta \mathrm{g}_{\mathrm{C}}$; these grains will grow rapidly to form abnormal grains. If $\Delta \mathrm{g}_{\mathrm{C}}>\Delta \mathrm{g}_{\max }$, then none of the grains will have $\Delta \mathrm{g} \geq \Delta \mathrm{g}_{\mathrm{C}}$. All of the grains will grow very slowly and stagnant grain growth will result.

Examples of systems with ordered solid/liquid interfaces which display these different types of grain growth behaviour include $\mathrm{MgO}$-excess $\mathrm{Pb}\left(\mathrm{Mg}_{1 / 3} \mathrm{Nb}_{2 / 3}\right) \mathrm{O}_{3}-35 \mathrm{~mol} \% \mathrm{PbTiO}_{3},{ }^{5} 3 \mathrm{CaO} . \mathrm{SiO}_{2}$ in a silicate melt, ${ }^{7} \mathrm{NbC}-\mathrm{Fe},{ }^{18} \mathrm{PMN}-\mathrm{PT}-\mathrm{PbO}-\mathrm{Li}_{2} \mathrm{O}{ }^{19}$, $\mathrm{BaTiO}_{3}{ }^{20}$ and $\mathrm{BaTiO}_{3}-\mathrm{TiO}_{2}-\mathrm{Al}_{2} \mathrm{O}_{3} .{ }^{21} \mathrm{~A}$ particularly striking example of the effect of interface structure is demonstrated by Yoon et al. for the TiC-WC-Co system. ${ }^{22}$ Rounded $(\mathrm{Ti}, \mathrm{W}) \mathrm{C}$ and faceted WC grains grow together in the same liquid Co matrix. The rounded $(\mathrm{Ti}, \mathrm{W}) \mathrm{C}$ grains show normal grain growth whereas the faceted WC grains show non-normal (nonstationary) grain growth (Fig. 2).

Equation [2] indicates that the starting mean radius of the powder can affect the grain growth behaviour of systems with ordered solid/liquid 

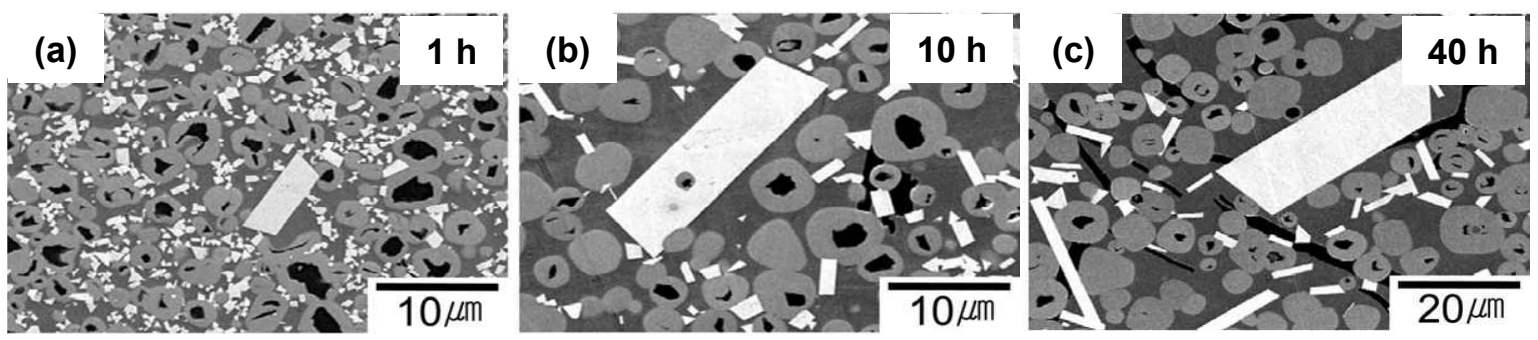

Figure 2 Microstructures of $70(25 \mathrm{TiC}-75 \mathrm{WC})-30 \mathrm{Co}(\mathrm{wt} \%)$ samples sintered at $1450^{\circ} \mathrm{C}$ for: (a) 1 hour; (b) 10 hours and (c) 40 hours (mean WC starting powder size $=0.5 \mu \mathrm{m})$. The rounded grains are $(\mathrm{Ti}, \mathrm{W}) \mathrm{C}$ and the faceted grains are $\mathrm{WC}^{22}$
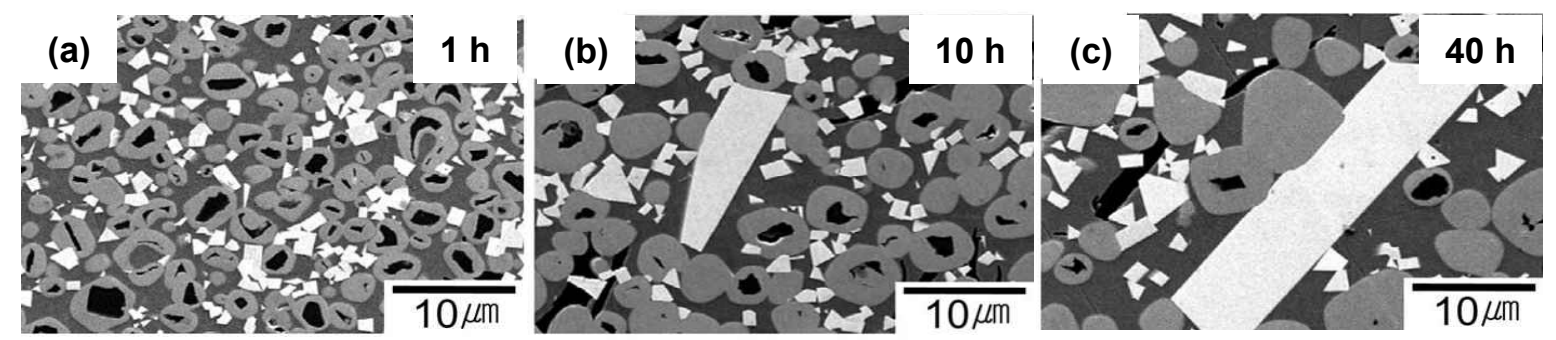

Figure 3 Microstructures of $70(25 \mathrm{TiC}-75 \mathrm{WC})-30 \mathrm{Co}$ (wt\%) samples sintered at $1450^{\circ} \mathrm{C}$ for: (a) 1 hour; (b) 10 hours and (c) 40 hours (mean WC starting powder size $=1.3 \mu \mathrm{m}){ }^{22}$
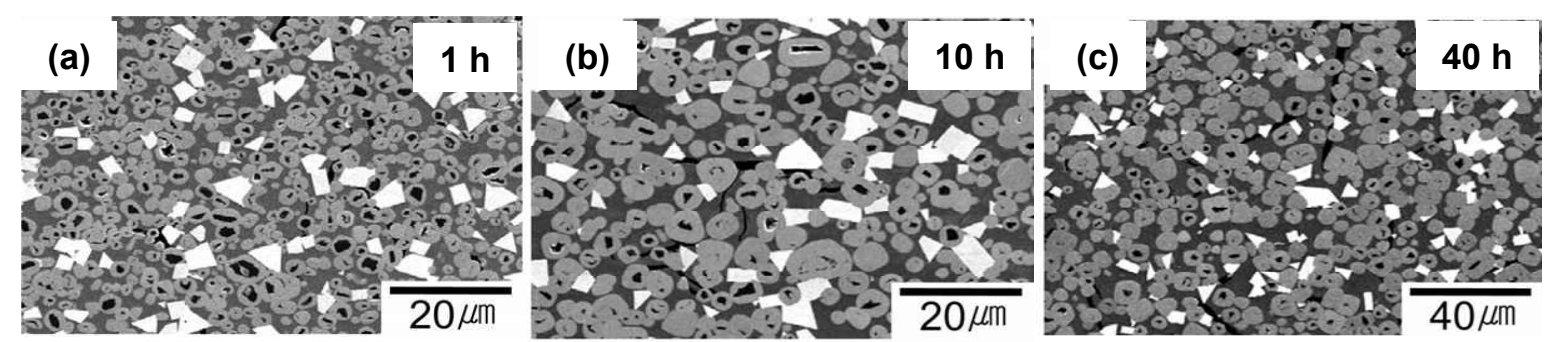

Figure 4 Microstructures of 70(25TiC-75WC)-30Co (wt\%) samples sintered at $1450^{\circ} \mathrm{C}$ for: (a) 1 hour; (b) 10 hours and (c) 40 hours (mean WC starting powder size $=4.1 \mu \mathrm{m}){ }^{22}$

interfaces. This is also shown in the work of Yoon et $a l^{22}$ If the starting mean size of the WC powder was fine $(0.5 \mu \mathrm{m})$, then abnormal grain growth occurred after sintering at $1450^{\circ} \mathrm{C}$ for 1 hour (Fig. 2). For a medium sized $\mathrm{WC}$ powder (mean size $=1.3 \mu \mathrm{m}$ ), abnormal grains only appeared after sintering for 10 hours (Fig. 3). The increased value of $\bar{r}$ causes a reduction in $\Delta \mathrm{g}_{\max }$ to a value below $\Delta \mathrm{g}_{\mathrm{C}}$. All of the grains have $\Delta \mathrm{g}<\Delta \mathrm{g}_{\mathrm{C}}$ and will grow only slowly. After 10 hours, a few grains have grown large enough for their driving force to be greater than $\Delta \mathrm{g}_{\mathrm{C}} .{ }^{17}$ These grains can now grow rapidly and form abnormal grains. For a coarse WC powder (mean size $=4.1 \mu \mathrm{m}$ ) abnormal grain growth did not take place even after 40 hours of sintering (Fig 4). The increased mean size of the starting WC powder causes $\Delta \mathrm{g}_{\max }<<\Delta \mathrm{g}_{\mathrm{C}}$. None of the grains grow large enough for their driving force to become greater than $\Delta \mathrm{g}_{\mathrm{C}}$ even after extended sintering.

From equation [3], it can be seen that the critical driving force varies strongly with the step free energy $\varepsilon$, which is the excess energy associated with the edge of the 2D nucleus. The value of $\varepsilon$ can be changed by changing the sintering temperature, sintering atmosphere or by adding dopants. An increase in vacancy concentration can reduce $\varepsilon$ by increasing the configurational entropy. ${ }^{23}$ So in the $\mathrm{SrTiO}_{3}$ system, an increase in vacancy concentration caused by $\mathrm{Nb}_{2} \mathrm{O}_{5}$ addition or by sintering in $\mathrm{H}_{2}$ caused the interface structure to change from ordered to disordered and a change in grain growth behaviour from abnormal to normal. ${ }^{24}$ In the PMN-PT-PbO- $\mathrm{Li}_{2} \mathrm{O}$ system, addition of $\mathrm{Li}_{2} \mathrm{O}$ and an increase in sintering temperature caused a transition from abnormal to pseudo-normal grain growth behaviour. ${ }^{19}$

Extended sintering times can cause changes in the grain growth behaviour of systems with ordered solid/liquid interfaces. The system $0.95\left(\mathrm{Na}_{0.5} \mathrm{Bi}_{0.5}\right) \mathrm{TiO}_{3}-0.05 \mathrm{BaTiO}_{3}$ consists of grains with faceted edges and rounded corners. This grain shape indicates that this system has a relatively low step free energy ${ }^{25}$ and hence a low value of $\Delta \mathrm{g}_{\mathrm{C}}$. Therefore the grain growth behaviour should be pseudo-normal when the driving force for grain growth is large. Indeed, $0.95\left(\mathrm{Na}_{0.5} \mathrm{Bi}_{0.5}\right) \mathrm{TiO}_{3}-0.05 \mathrm{BaTiO}_{3}$ sintered at $1200^{\circ} \mathrm{C}$ initially shows apparently normal grain growth. ${ }^{26}$ However, on extended sintering ( approx. $>4$ hours), abnormal grains appear (Fig. 5). When the samples are initially sintered, $\Delta \mathrm{g}_{\max }$ is high 

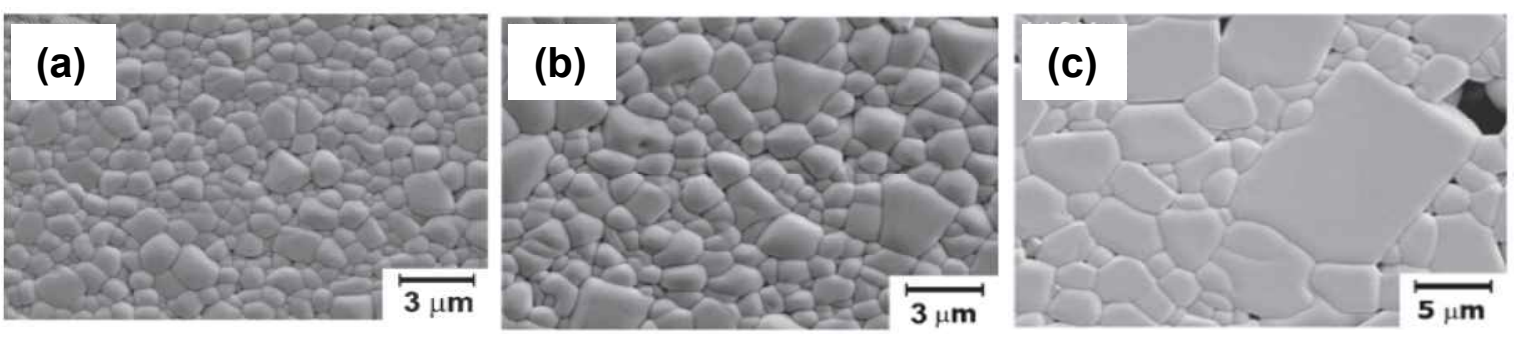

Figure $50.95\left(\mathrm{Na}_{0.5} \mathrm{Bi}_{0.5}\right) \mathrm{TiO}_{3}-0.05 \mathrm{BaTiO}_{3}$ ceramics sintered at $1200^{\circ} \mathrm{C}$ for (a) 1 , (b) 4 and (c) 24 hours. $^{26}$

due to the small mean grain radius (Equation [1]). Many grains can grow and pseudo-normal grain growth takes place. However, $\bar{r}$ increases with sintering time, causing $\Delta \mathrm{g}_{\max }$ to decrease and eventually become $\approx \Delta \mathrm{g}_{\mathrm{C}}$. Most of the grains will now have $\Delta \mathrm{g}<\Delta \mathrm{g}_{\mathrm{C}}$ and will almost stop growing. A small number of grains with $\Delta \mathrm{g}$ $\geq \Delta \mathrm{g}_{\mathrm{C}}$ will continue to grow appreciably, forming abnormal grains.

If screw dislocations are present on the grain surface, then the growth rate vs. driving force curve is parabolic rather than exponential. ${ }^{9}$ Grain growth can take place even at $\Delta \mathrm{g}<\Delta \mathrm{g}_{\mathrm{C}}$. Nevertheless, as the rate of growth by screw dislocation-assisted growth is lower than that by diffusion-limited growth, the behaviour is similar (though less pronounced) to that predicted by $2 \mathrm{D}$ nucleation and growth in terms of the relative values of $\Delta \mathrm{g}_{\mathrm{C}}$ and $\Delta \mathrm{g}_{\max }$. When a limited number of grains have high dislocation densities, these grains can grow faster than others and may form abnormal grains. $^{27}$

Single crystals of ceramics with ordered solid/liquid interfaces can be grown by the solid state crystal growth method. A single crystal (seed crystal) is buried in the ceramic powder, pressed and sintered. During sintering, the seed crystal acts like an abnormal grain and a single crystal of the ceramic composition grows onto it (Fig. 6). ${ }^{28}$ Alternatively, the seed crystal can be placed on top of a pre-sintered ceramic substrate and annealed. This technique has been used to grow crystals such as $\mathrm{BaTiO}_{3},{ }^{29},{ }^{30} \mathrm{~Pb}\left(\mathrm{Mg}_{1 / 3} \mathrm{Nb}_{2 / 3}\right) \mathrm{O}_{3}-$ $\mathrm{PbTiO}_{3}{ }^{19}$ and $\left(\mathrm{K}_{0.5} \mathrm{Na}_{0.5}\right) \mathrm{NbO}_{3}{ }^{28}$ and is particularly useful for incongruently melting systems. Single crystals grown by this method are often very porous. The density of the single crystal can be increased by hot pressing the ceramic matrix before crystal growth ${ }^{28}$ or by growing the crystal in a hot press. ${ }^{31}$

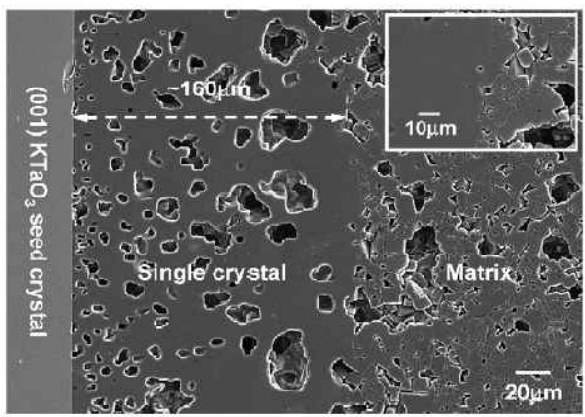

Figure $6\left(\mathrm{~K}_{0.5} \mathrm{Na}_{0.5}\right) \mathrm{NbO}_{3}$ single crystal grown on a (001) $\mathrm{KTaO}_{3}$ seed crystal. ${ }^{28}$

\section{Grain Growth in Single Phase Systems}

The grain growth behaviour in single phase systems also depends on the interface structure of the grain boundaries. Both disordered (rough) and ordered (faceted) grain boundaries have been observed in single phase materials. ${ }^{32,33,34,35,36,37}$ Several authors have proposed models in which ordered grain boundaries migrate by the nucleation and growth of steps, analogous to the 2D nucleation and growth model given above. ${ }^{38,39}$ Indeed, ordered grain boundaries in $\mathrm{Au}$ thin films were found to move by the nucleation and growth of atomic-height steps on the growing boundary. ${ }^{40}$

Several studies in $\mathrm{BaTiO}_{3}$ have shown that normal grain growth takes place when the grain boundaries have a disordered structure and abnormal grain growth takes place when the boundaries have an ordered structure. ${ }^{41,42}$ The grain growth behaviour in $\mathrm{BaTiO}_{3}$ is quite unique. When sintered in air at $1250^{\circ} \mathrm{C}$, where all of the grain boundaries are faceted, $\mathrm{BaTiO}_{3}$ shows abnormal grain growth assisted by $\{111\}$ twins [Fig. 7(a)]. ${ }^{37}$ When the oxygen partial pressure $P_{O_{2}}$ decreases to $8 \times 10^{-12} \mathrm{~atm}$, where $<10 \%$ of the grain boundaries are rough (disordered), the $\{111\}$ twins no longer form and stagnant grain growth occurs [Fig. 7(b)]. With further decrease in $P_{\mathrm{O}_{2}}$ to $8 \times 10^{-18} \mathrm{~atm}$, where $\sim 20 \%$ of the grain boundaries are rough, the grain growth behaviour changes to abnormal [Fig. 7(c)]. Finally, when the $P_{O_{2}}$ decreases to $4 \times 10^{-19}$ atm and $\sim 90 \%$ of the grain boundaries are rough, the grain growth behaviour changes to normal [Fig. 7(d)].

Experiments in other systems have also shown a correlation between grain boundary structure and grain growth behaviour. In the $\left(\mathrm{K}_{0.5} \mathrm{Na}_{0.5}\right) \mathrm{NbO}_{3}$ system, changing the sintering atmosphere from air to $\mathrm{H}_{2}$ caused the grain shape to change from faceted with sharp corners to faceted with rounded corners. ${ }^{43}$ The grain growth behaviour changed from abnormal grain growth to delayed abnormal grain growth, similar to that of $0.95\left(\mathrm{Na}_{0.5} \mathrm{Bi}_{0.5}\right) \mathrm{TiO}_{3}-0.05 \mathrm{BaTiO}_{3} .{ }^{26} \mathrm{~A}$ correlation between grain boundary structure (disordered or ordered) and grain growth behaviour (normal or abnormal) has also been observed in several metallic systems. ${ }^{32,33,34}$ 

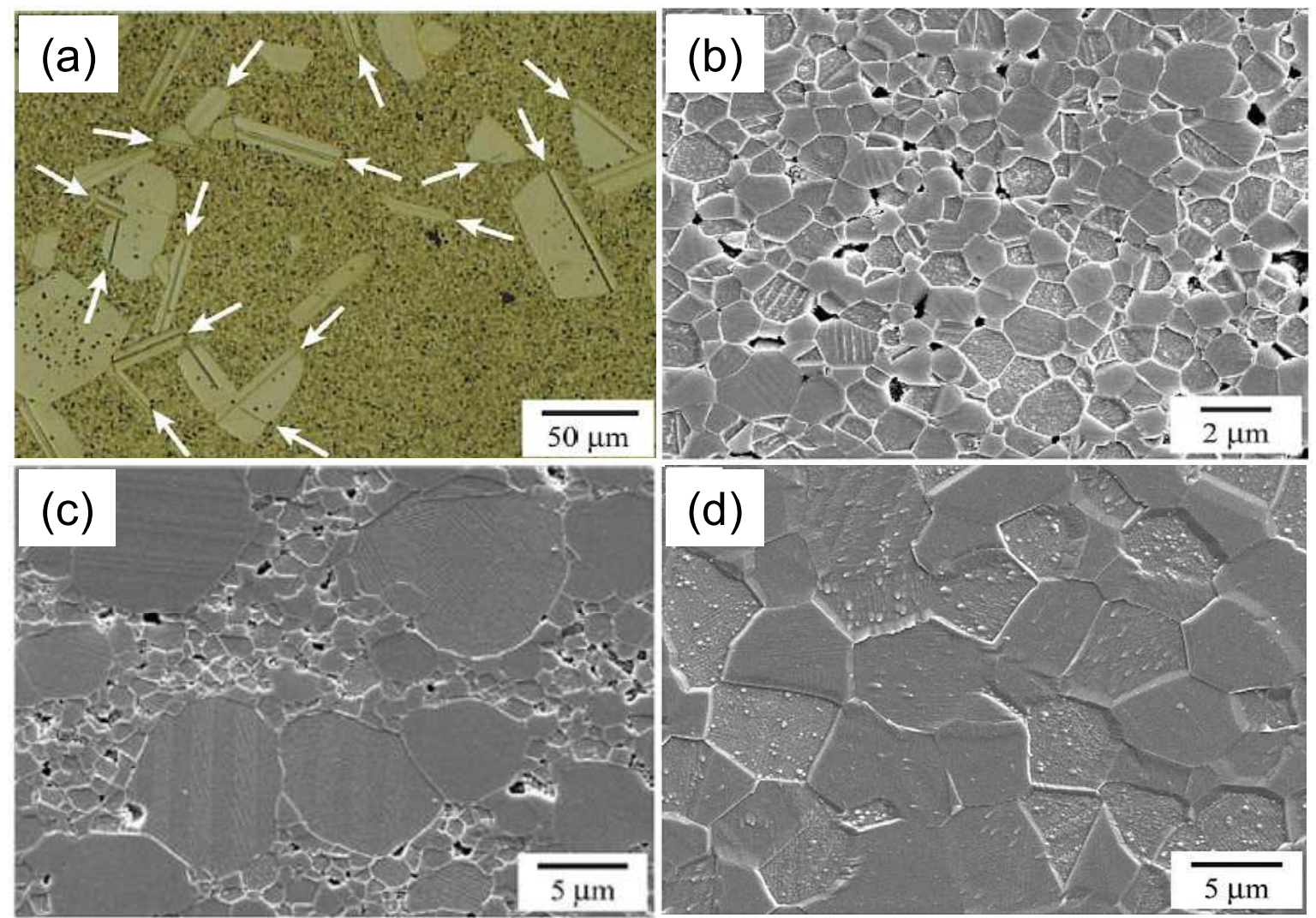

Figure $70.1 \mathrm{~mol} \% \mathrm{TiO}_{2}$ excess $\mathrm{BaTiO}_{3}$ ceramics sintered at $1250^{\circ} \mathrm{C}$ under $P_{O_{2}}$ of : (a) 0.2 atm (air) for $10 \mathrm{~h}$; (b) $8 \times 10^{-12}$ atm $\left(70 \mathrm{CO}-30 \mathrm{CO}_{2}\right)$ for $24 \mathrm{~h}$; (c) $8 \times 10^{-18}$ atm $\left(85 \mathrm{~N}_{2}-15 \mathrm{H}_{2}\right)$ for $50 \mathrm{~h}$ and (d) $4 \times 10^{-19}$ atm $\left(50 \mathrm{~N}_{2}-50 \mathrm{H}_{2}\right)$ for $50 \mathrm{~h}$. White arrows indicate $\{111\}$ twins. $^{37}$

\section{CONCLUSIONS}

Grain growth behaviour in both two-phase and single phase materials is dependant on the interface structure. On an atomic scale, interfaces can be disordered (rough) or ordered (smooth/faceted). For disordered interfaces, grain growth is limited by the rate at which atoms can diffuse to the growing grain. Grain growth rate is an almost linear function of the driving force for grain growth and normal grain growth occurs. For ordered interfaces, grain growth is limited by the rate at which atoms can permanently attach to the growing grain. For 2D-nucleation controlled growth, grain growth is an exponential function of the driving force. Grain growth is very slow at driving forces lower than the critical driving force for growth $\Delta \mathrm{g}_{\mathrm{C}}$, increasing rapidly for driving forces higher than the critical driving force. Depending on the relative values of the critical and maximum driving forces, different types of grain growth can occur: pseudo-normal, abnormal, stagnant and delayed abnormal. The principles of microstructural development in terms of the coupling effect between the critical driving force for growth $\Delta g_{C}$ and the maximum driving force $\Delta g_{\max }$ have therefore been deduced. By controlling sintering temperature, atmosphere, dopant addition and powder size, it is possible to control the relative values of the critical and maximum driving forces and thereby control the grain growth behaviour.

\section{ACKNOWLEDGEMENTS}

This work was supported by the Priority Research Centers Program through the National Research Foundation of Korea (NRF) funded by the Ministry of Education, Science and Technology (grant no. 20090094039).

${ }^{1}$ I. M. Lifshitz and V. V. Slyozov, J. Phys. Chem. Solids, 19, 35-50 (1961).

${ }^{2}$ C. Wagner, Z. Electrochem, 65, 581-91 (1961).

${ }^{3}$ G. W. Greenwood, "The Mechanism of Phase

Transformations in Crystalline Solids", Institute of Metals, London (1969) pp. 103-110.

${ }^{4}$ J. W. Martin and R. D. Doherty, "Stability of

Microstructures in Metallic Systems", Cambridge

University Press, Cambridge (1976) pp. 182-187.

${ }^{5}$ C. E. Seo and D. Y. Yoon, J. Am. Ceram. Soc., 88 [4], 963-967 (2005).

${ }^{6}$ H. Moon, B. K. Kim and S.-J. L. Kang, Acta. Mater., 49, 1293-1299 (2001).

${ }^{7}$ S. K. Kwon, S. H. Hong, D. Y. Kim and N. M.

Hwang, J. Am. Ceram. Soc., 83 [5], 1247-1252 (2000). 
${ }^{8}$ J. P. Hirth and G. M. Pound, "Condensation and Evaporation: Nucleation and Growth Kinetics", Pergamon Press, Oxford (1963) pp. 77-148.

${ }^{9}$ W. K. Burton, N. Cabrera and F. C. Frank, Philos. Trans. R. Soc. London, Ser. A, 243, 299-358 (1951).

${ }^{10}$ S. Y. Chung and S.-J. L. Kang, J. Am. Ceram. Soc., 83 [11], 2828-2832 (2000).

${ }^{11}$ S. Šturm, A. Rečnik, C. Scheu and M. Čeh, J. Mater. Res., 15 [10], 2131-2139 (2000).

${ }_{12}$ A. Rečnik, M. Čeh and D. Kolar, J. Eur. Ceram. Soc., 21, 2117-2121 (2001).

${ }^{13}$ A. Rečnik, Acta Chim. Slov., 48, 1-50 (2001).

${ }^{14}$ B. K. Lee, Y. I. Jung, S.-J. L. Kang and J. Nowotny, J. Am. Ceram. Soc., 86 [1], 155-60 (2003).

${ }^{15}$ J. P. van der Erden, "Handbook of Crystal Growth Vol. 1, Fundamentals Part A, Thermodynamics and Kinetics", Ed. by D. T. J. Hurle, Elsevier Science Publishers, Amsterdam (1993) pp. 311-475.

${ }^{16}$ S.-J. L. Kang, M. G. Lee and S. M. An, J. Am. Ceram. Soc., 92 [7], 1464-1471 (2009).

${ }^{17}$ Y. I. Jung, D. Y. Yoon and S.-J. L. Kang, J. Mater. Res., 24 [9], 2949-2959 (2009).

${ }^{18}$ S.-J. L. Kang, "Sintering:Densification, Grain Growth \& Microstructure", Elsevier ButterworthHeinemann, Oxford (2005) p. 205-226.

${ }^{19}$ J. G. Fisher, M. S. Kim, H. Y. Lee and S.-J. L. Kang, J. Am. Ceram. Soc., 87 [5], 937-942 (2004)

${ }^{20}$ J. K. Liou, M. H. Lin and H. Y. Lu, J. Am. Ceram. Soc., 85 [12], 2931-2937 (2002).

${ }^{21}$ J. G. Fisher, S. Y. Choi and S.-J. L. Kang, J. Am. Ceram. Soc., 89 [7], 2206-2212 (2006).

${ }^{22}$ B. K. Yoon, B. A. Lee and S.-J. L. Kang, Acta Mater., 53, 4677-4685 (2005).

${ }^{23}$ E. D. Williams, Surf. Sci., 299/300, 502-524 (1994).

${ }^{24}$ S. Y. Chung, D. Y. Yoon and S.-J. L. Kang, Acta Mater., 50, 3361-3371 (2002).

${ }^{25}$ C. Rottman and M. Wortis, Phys. Rep., 103 [1], 5979 (1984).

${ }^{26}$ K. S. Moon and S.-J. L. Kang, J.Am. Ceram. Soc., 91 [10], 3191-3196 (2008).

${ }^{27}$ S. Y. Chung and S.-J. L. Kang, J. Am. Ceram. Soc., 83 [11], 2828-2832 (2000).

${ }^{28}$ J. G. Fisher, A. Benčan, J. Holc, M. Kosec, S. Vernay and D. Rytz, J. Cryst. Grow., 303, 487-492 (2007).

${ }^{29}$ T. Yamamoto and T. Sakuma, J. Am. Ceram. Soc., 77 [4], 1107-1109 (1994).

${ }^{30}$ S. Y. Choi, D. Y. Yoon and S.-J. L. Kang, Acta Mater., 52, 3721-3726 (2004).

${ }^{31}$ J. G. Fisher, A. Benčan, M. Kosec, S. Vernay and D. Rytz, J. Am. Ceram. Soc., 91 [5], 1530-1507 (2008).

${ }^{32}$ S. B. Lee, D. Y. Yoon and M. F. Henry, Acta Mater., 48, 3071-3080 (2000)

${ }^{33}$ J. B. Koo and D. Y. Yoon, Metal. Mater. Trans. A, 32, 469-475 (2001).

${ }^{34}$ J. S. Choi and D. Y. Yoon, ISIJ International.41 [5], 478-483 (2001).

${ }^{35}$ C. W. Park, D. Y. Yoon, J. E. Blendell and C. A.

Handwerker, J. Am. Ceram. Soc., 86 [4], 603-611 (2003).

${ }^{36}$ S. Y. Choi and S.-J. L. Kang, Acta Mater., 52, $2937-$ 2943 (2004).
${ }^{37}$ Y. I. Jung, S. Y. Choi and S.-J. L. Kang, Acta Mater., 54, 2849-2855 (2006).

${ }^{38}$ C. M. F. Rae and D. A. Smith, Phil. Mag. A, 41, 47792 (1980).

${ }^{39}$ S. E. Babcock and R. W. Balluffi, Acta Metall., 37 [9], 2367-2376 (1989).

${ }^{40}$ K. L. Merkle and L. J. Thompson, Mat. Lett., 48, 188-193 (2001).

${ }^{41}$ B. K. Lee, S. Y. Chung and S.-J. L. Kang, Acta Mater., 48, 1575-1580 (2000).

${ }^{42}$ Y. K. Cho, S.-J. L. Kang and D. Y. Yoon, J. Am. Ceram. Soc., 87 [1], 119-124 (2004).

${ }^{43}$ J. G. Fisher and S.-J. L. Kang, J. Eur. Ceram. Soc., 29, 2581-2588 (2009).

(Received January 13, 2010; Accepted July 10, 2010) 